\title{
Hearing Care for Older Adults: Beyond the Audiology Clinic
}

\author{
Marie Öberg \\ Linköping University Post Print
}

Tweet

N.B.: When citing this work, cite the original article.

Original Publication:

Marie Öberg, Hearing Care for Older Adults: Beyond the Audiology Clinic, 2015, American Journal of Audiology, (24), 2, 104-107.

http://dx.doi.org/10.1044/2015_AJA-14-0077

Copyright: American Speech-Language-Hearing Association http://www.asha.org/default.htm

Postprint available at: Linköping University Electronic Press

http://urn.kb.se/resolve?urn=urn:nbn:se:liu:diva-120657 


\section{Hearing Care for Older Adults: Beyond the Audiology Clinic}

\section{Marie Öberg}

Technical Audiology, Department of Clinical and Experimental Medicine, Faculty of Health Sciences, Linköping University, Department of Otorhinolaryngology in Linköping, Anaesthetics, Operations and Specialty Surgery Center, County Council of Östergötland, Sweden. The Swedish Institute for Disability Research, Linnaeus Centre HEAD, Department of Behavioral Sciences and Learning,Linköping University, Sweden

Purpose: The purpose of this article was to highlight the importance of hearing health care beyond the clinic for older people with impaired hearing.

Method: To emphasize factors affecting the success of audiologic rehabilitation for older people and to describe practical clinical and community-based strategies to promote successful hearing health care.

Result: Older people are not always aware of the extent of their hearing loss, they may not always expect to benefit from using a hearing aid, and they often have low self-efficacy for managing to learn to use hearing aids. Increased knowledge and support from other health professionals, family caregivers and significant others could optimize older peoples' participation in everyday activities.

Conclusion: Further work is needed to develop new interventions for older people with impaired hearing and to increase collaboration with general practitioners as well as other health-care professionals.

Keyword, Older, self-efficacy, significant other

How could we best help older people who have hearing impairment? Older people seeking (or not seeking) hearing health care are not always aware of the extent of their hearing loss. 
Sometimes they do not believe they would benefit from using a hearing aid. They often have low self-efficacy being afraid of not having the skills to learn new things as for example how to handle the hearing aids. Many older individuals have mild cognitive impairment and need assistance from significant others or caregivers. In addition to typical clinical-based audiological rehabilitation service, a community-based health-promotion approach would be advantageous in increasing awareness, increasing information and providing a more positive outlook about hearing health care options. Such an approach could be useful in predisposing older adults to seek help and in enabling them to achieve greater benefit from audiologic rehabilitation. Community-based strategies to promote successful hearing health may also be crucial in reinforcing the maintenance of hearing aid use and hearing-related behavior changes after rehabilitation has been provided. This approach would involve increased partnerships between audiologists and other health-care professionals and service providers working with older adults in the community, including primary care physicians and geriatric physicians. This presentation includes practical examples of how we have tried to implement this approach in Linköping, Sweden and includes some data from our completed research studies.

Awareness in the community about hearing difficulties and the positive benefits of audiological rehabilitation needs to be increased. What individuals have heard in the community, from friends, relatives, and the media affects their beliefs, and in turn their decisions about when to seek hearing health care. To increase awareness of hearing-related problems and increase knowledge about the potential benefits of audiologic rehabilitation, professionals from the clinic in Linköping regularly disseminate information in the community. This could be in the form of lectures to nursing students, talks to the staff working in nursing homes, talks for members in seniors' associations and the Hard of Hearing Association. 
There are several personal factors that influence help-seeking (Knudsen, Oberg, Nielsen, Naylor \& Kramer, 2010), but external factors also need to be considered. Several studies indicate that general practitioners dismiss hearing problems or do not refer due to lack of conviction about the benefits of hearing rehabilitation for older adults (Gilliver \& Hickson, 2011; Laplante-Lévesque et al, 2012; Wallhagen \& Pettengill, 2008). In the study by Wallhagen and Pettengill (2008), older participants were interviewed and $85 \%$ indicated that there had been no questions related to hearing difficulties when they had visited physicians. The study by Laplante Lévesque et al. (2012) also confirmed the lack of referrals to audiology by physicians. In our study of people who were 87 years old (Öberg, Marcusson, Nägga \& Wressle, 2012), the participants were asked about their main reason for not acquiring hearing aids. About $10 \%$ responded that they "never received a recommendation to seek hearing health care" and the most common answers referred to the alternatives "hearing difficulties not severe enough" $(38 \%)$ and "it is normal to have hearing loss at my age" (19\%). These reasons for not pursuing audiologic rehabilitation are consistent with the findings of several studies (Gussekloo et al, 2003; Humes, Wilson, \& Humes, A., 2003; Kochkin, 2007; Meyer et al, 2011). Nevertheless, individuals in our region can seek audiologic rehabilitation without a referral. In the study investigating hearing difficulties in people living in Linköping who were 85 years old, it was found that $59 \%$ of those who reported subjective hearing difficulties also owned a hearing aid and $47 \%$ used it more than 8 hours per day (Öberg et al., 2012). This was a somewhat higher uptake rate than in other studies (Chia et al, 2007; Chien \& Lin, 2012).

People's beliefs about hearing aids and rehabilitation may be understood within the framework of the Health Belief Model. It is a psychosocial model of health behavior change that was developed to predict the likelihood of a person taking recommended preventive 
health action and to understand a person's motivation to seek health care (Hochbaum 1958; Rosenstock, 1974). Health behavior change is mediated by the five health constructs: (Rosenstock, Strecher \& Becker, 1988) 1. perceived susceptibility (i.e., the likelihood an individual will suffer from hearing loss), 2. perceived severity of hearing loss (i.e., severity of the hearing loss and its consequences), 3. perceived barriers to rehabilitation (i.e., the obstacles and psychosocial costs of conducting an intervention), 4. perceived self-efficacy (i.e., to what degree the individual thinks he/she could manage to use hearing aids) and 5. perceived benefit of the rehabilitation (i.e., the believed effects of the rehabilitation). In addition, cues to action can motivate behavior change.

In two of our earlier studies, which included first-time hearing aid users, initial interview questions were added to identify the benefits and barriers to hearing aid rehabilitation and hearing aid self-efficacy (Öberg, Andersson, Wänström \& Lunner, 2008, 2009). To investigate the benefits and barriers, the participants were asked an open-ended question about what they had heard about hearing aids. The answers were analyzed and categorized into three categories: 1 . those who only had heard negative information, 2. those who had heard negative and positive information, and 3. those who had heard only positive information. Most participants mentioned both negative and positive aspects. Differences were found when the participants were divided into three age groups (55-65, 66-75 and 76-80 year). Specifically, $20 \%$ of the youngest group but only $6-7 \%$ of the two older groups reported only having heard positive information. In contrast, in the older groups, $29 \%$ mentioned only negative aspects, but this was the case for only $16 \%$ of the youngest group. Similarly, in the study by Saunders, Teahen-Frederick, Silverman and Papesh, (2013), it was shown that many individuals perceived barriers to using hearing aids. To investigate hearing aid self-efficacy, the participants were asked the open question: "When will you use your hearing aids"? As shown in Figure 1, the answers were categorized into the three categories (When I need it, 
Always, Doubtful about when to use it), where the most common answer of the younger participants was Always, but the most common answer of the oldest participants was to be doubtful. Typical comments from those who were doubtful were "I will try to use them" and "I hope I could get used to them".

When working with older people affected by multiple physical and/or mental health issues, it is even more important to determine the most appropriate rehabilitation options for each individual. In the clinic, we spent more time with these individuals because it is necessary to have an opportunity to repeat information and to thoroughly practice the handling of the aids. Since individuals with cognitive impairment may easily become distracted, home visits can make it easier for them to learn new things because they may be less distracted in their own environment. When visiting the individual in their home, it is also easier to give suggestions about assistive devices, communications strategies and/or perform telephone training. Decision-making and rehabilitation planning, delivery of services and monitoring of these individuals often demands increased collaboration with other health-care professionals, family caregivers and significant others. Together, opportunities to optimize participation in everyday activities can be enhanced. Significant others and caregivers must be integrated into each phase of rehabilitation and they are also included in clinic appointments whenever possible. Engagement and support of the significant others are important to the success of the individual (Hallberg \& Barrenäs, 1994; Hickson, Meyer, Lovelock, Lampert \& Khan, 2014). Meyer, Hickson and Fletcher (2014) found that individuals who report having a supportive significant other also reported higher-self-efficacy. To best help an individual living in a nursing home, it is important to establish and maintain contact with the individual's designated decision-maker, especially when trying to work out the best solution for the specific needs of the individual. Some nurses working in this area have undergone an in-depth education which meant they could help older adults with hearing loss, and to train 
other nurses in how to handle hearing aids (individual contact persons). More nurses working in nursing homes need this education and it is important to try to increase opportunities for education. There are ongoing initiatives to try to develop new interventions for older people. In our clinic, we offer The Active Communication Education program (ACE) (Hickson, Worrall, \& Scarinci, 2007). The primary aims of the ACE program are to reduce communication difficulties in everyday life and to improve quality of life (Hickson et al, 2007). The ACE program uses a problem-solving interactive approach in which participants are encouraged to discuss the communication difficulties that they experience and, together with the group members and the facilitators, they generate and practice communication solutions. In a study of ACE with participants who were 87 years old, we found that these older adults attended the sessions with enthusiasm and that the program increased their ability to cope with the hearing loss and the problems it creates (Öberg, Bohn, Larsson, \& Hickson, 2014). The ACE program has shown to be effective also for a somewhat younger Swedish population (Öberg, Bohn, \&Larsson, 2014)

Even if the studies of older people with hearing difficulties in Linköping, Sweden seem to be rather positive, we still need to work further to develop new interventions for this population. We would like to expand inter-professional education and to further increase collaboration with general practitioners and other health-care professionals.

Acknowledgement: These studies were supported by grants from the Oticon Foundation Oticon A/S, the Swedish Institute of Assistive Technology and the Swedish Hard of Hearing Association. 


\section{References}

Chia, E.M., Wang, J.J., Rochtchina, E., Cumming, R., Newall, P., \& Mitchell, P. (2007). Hearing Impairment and Health-Related Quality of Life: The Blue Mountains Hearing Study. Ear and Hearing, 28, 187-195.

Chien, W., \& Lin, F.R. (2012). Prevalence of Hearing Aid Use Among Older Adults in the United States. Archives internal medicine, 172, 292-293.

Gilliver, M., \& Hickson, L. (2011). Medical practitioners's attitude to hearing rehabilitation for older adults. International Journal of Audiology, 50, 850-856.

Gussekloo, J., von Faber, M., Eekhof, J., de Laat, J., Hulshof, J., van Dongen, E., et al. (2003). Auditory rehabilitation of older people from the general population- the Leiden 85-plus study. British Journal of General Practice, 53, 536-540.

Hallberg, L., \& Barrenäs, M-L. (1994). Group rehabilitation of middle-aged males with noise-induced hearing loss and their spouses: evaluation of short- and long-term effects. British Journal of Audiology, 28, 71-79. 
Hickson, L., Meyer, C., Lovelock, K., Lampert, M., \& Khan (2014). Factors associated with success with hearing aids in older adults. International Journal of Audiology, 53, S18-S27.

Hickson, L., Worrall L., \& Scarinci, N. (2007) Active Communication Education (ACE): A program for older people with hearing impairment. Brackley, United Kingdom: Speechmark.

Hochbaum, I.M. (1958). Public Participation in Medical Screening Programs: A SocioPsychological Study. Public Health Service Publication No. 572. Washington 25 D.C., United States Government Printing Office.

Humes, L., Wilson, D., \& Humes, A. (2003). Examination of differences between successful and unsuccessful elderly hearing aid candidates matched for age, hearing loss and gender. International Journal of Audiology, 42, 432-441.

Knudsen, L., Oberg, M., Nielsen, C., Naylor, G., \& Kramer S.E. (2010). Factors influencing help seeking, hearing aid uptake, hearing aid use and satisfaction with hearing aids: A review of the literature. Trends in Amplification, 14, $127-$ 154. 
Kochkin, S. (2007). Marketrak VII: obstacles to adult non-user adoption to hearing aids. The Hearing Journal, 60, 24-51.

Laplante-Lévesque, A., Knudsen, L.V., Preminger, J.E., Jones, L., Nielsen, C., Öberg, M., et al. (2012). Hearing help-seeking and rehabilitation: Perspectives of adults with hearing impairment. International Journal of Audiology, 51, 93-102.

Meyer, C., Hickson, L., \& Fletcher, A. (2014). Identifying the barriers and facilitators to optimal hearing aid self-efficacy. International Journal of Audiology, 53, (Suppl 1), 28-37.

Meyer, C., Hickson, L., Khan, A., Hartley, D., Dillon, H., \& Seymour, J. (2011). Investigation of the action taken by adult who failed a telephone-based hearing screening. Ear and Hearing, 32,720-731.

Rosenstock, I.M. (1974). Historical origins of the Health Belief Model. Health Education Behavior, 2, 328-335.

Rosenstock, I.M., Strecher, V.J., \& Becker, M.H. (1988). Social Learning Theory and the Health Belief Model. Health Education Behavior, 15, 175-183. 
Saunders, G., Teahen-Frederick, M., Silverman, S., \& Papesh, M. (2013). Application of the health belief model: Development of the hearing beliefs questionnaire (HBQ) and its associations with hearing health behaviors. International Journal of Audiology, 52, 558-567.

Wallhagen, M., \& Pettengill, E. (2008). Hearing impairment: significant but underassessed in primary care settings. Journal Gerontological Nursing, 34, 36-42.

Öberg, M., Andersson, G., Wänström, G., \& Lunner, T. (2008). The effects of a soundawareness pre-fitting intervention: A randomized controlled trial. Audiological Medicine, 6, 129-140.

Öberg, M., Andersson, G., Wänström, G., \& Lunner, T. (2009). The effects of a pre-fitting intervention on hearing aid benefit: a randomized controlled trial. Audiological Medicine, 7, 211-225.

Öberg, M., T. Bohn., \& Larsson. U. (2014). Short- and long-term effects of the modified Swedish version of the Active Communication Education (ACE) program for adults with hearing loss. Journal of the American Academy Audiology, 25, 848858. 
Öberg, M., Bohn, T., Larsson, U., \& Hickson, L. (2014). A preliminary evaluation of the Active Communication Education program in a sample of 87-year-old hearing impaired individuals. Journal of the American Academy Audiology, 25, 219-228.

Öberg, M., Marcusson, J., Nägga, K., \& Wressle, E. (2012). Hearing difficulties, uptake, and outcomes of hearing aids in people 85 years of age. International Journal of Audiology, 51, 108-115. 


\section{When will you use the Hearing Aids?}

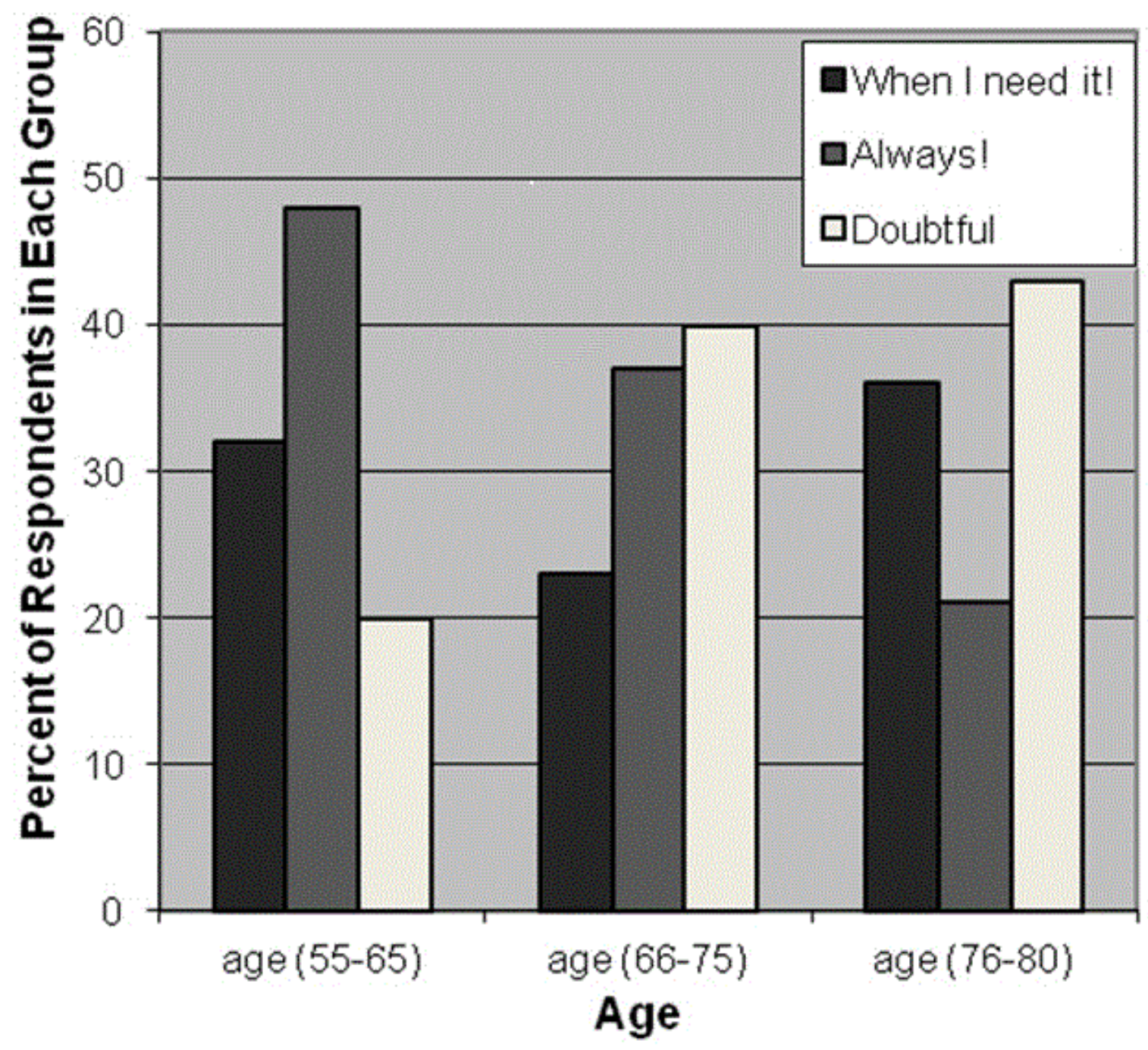


Fig. 1. Comparison between different age groups according to the question "When will you use the hearing aids"? 